(2) Open Access Full Text Article

\title{
Acute effects of consumption of energy drinks on intraocular pressure and blood pressure
}

This article was published in the following Dove Press journal:

Clinical Optometry

I5 April 20I I

Number of times this article has been viewed

\section{A Alex llechie Sandra Tetteh \\ Department of Optometry, University of Cape Coast, Ghana}

Background: Energy drinks contain a wide variety of ingredients including caffeine, for which there have been conflicting reports regarding its effects on intraocular pressure (IOP) and blood pressure. The aim of this study was to investigate the acute effects of an energy drink (Red Bull $\left.{ }^{\mathbb{}}\right)$ on the IOP and blood pressure of healthy young adults.

Methods: Thirty healthy university students of either gender, aged 18-30 (mean 23.20 2.81 ) years were randomly selected to participate in this study. The subjects were randomly divided into two groups (experimental and control) and were asked to abstain from caffeine for 48 hours prior to and during the study. Baseline IOP and blood pressure were measured. The experimental group ( $\mathrm{n}=15$ ) consumed one can of the energy drink (containing $85 \mathrm{mg}$ of caffeine in $250 \mathrm{~mL}$ ) and measurements were repeated at 30,60, and 90 minutes, while the control group drank $250 \mathrm{~mL}$ of water and were tested over the same time period.

Results: When compared with baseline, a significant decrease $(P<0.05)$ in mean IOP at 60 and 90 minutes was observed in the experimental group. There was no corresponding change in systolic or diastolic blood pressure.

Conclusion: Our results suggest that energy drinks (ie, Red Bull) produce a significant reduction in IOP but have no effect on blood pressure. These findings may be interpreted as reflecting the effect of the combination of caffeine and taurine in the Red Bull energy drink. This effect may result from the known hypotensive effect of taurine, and warrants further study.

Keywords: acute effect, intraocular pressure, blood pressure, glaucoma, caffeine, taurine

\section{Introduction}

Energy drinks (eg, Power Horse ${ }^{\circledR}$, Red Bull ${ }^{\circledR}$, and Rox ${ }^{\circledR}$ ) are caffeinated beverages designed primarily to increase the consumer's physical endurance. Companies that market these products usually target young adults. A survey of energy drink consumption by young people revealed that $51 \%$ reported consuming at least one energy drink per month. ${ }^{1}$

These beverages contain many ingredients, including caffeine (80-500 mg) and an amino acid derivative called taurine (1000-2000 mg). Sugar, vitamins, and other nutritional supplements may also be included. ${ }^{2}$ Researchers have studied caffeine and taurine, and shown that they are the most physiologically active ingredients in energy drinks. ${ }^{3}$

It should be noted that, although energy drinks have been sold worldwide for more than a decade, only a few published studies have examined their effects on health and well-being. Steinke and Lanfear ${ }^{4}$ investigated the effects of energy drink consumption on hemodynamic and electrocardiogram (ECG) parameters in healthy young adults,
Correspondence: A llechie Department of Optometry, University of Cape Coast, Ghana Tel +23324417 0148

Email drilechie@yahoo.com 
and reported a significantly increased heart rate and blood pressure within 4 hours. On the first day, baseline measurements of blood pressure, heart rate, and ECG were taken. The participants then drank two cans of an energy drink containing caffeine $80 \mathrm{mg}$ and taurine $1000 \mathrm{mg}$. Blood pressure, heart rate, and ECG measurements were repeated at 30 minutes, and at hours 1, 2, 3, and 4 after consumption. This continued for the next 5 days, then the same procedures used on the first day were repeated on day 7 . Within 4 hours of energy drink consumption, maximum systolic blood pressure increased by $7.9 \%$ on day 1 and by $9.6 \%$ on day 7 , and within 2 hours of energy drink consumption, diastolic blood pressure increased by $7 \%$ and $7.8 \%$ on days 1 and 7 , respectively. It was also found that heart rate increased by $7.8 \%$ on day 1 and by $1 \%$ on day 7. No significant ECG changes were observed.

In another study, the influence of a multicomponent energy drink and its individual ingredients on the heart was compared. Red Bull containing both taurine and caffeine, a similar drink containing caffeine but no taurine, and a placebo drink without taurine or caffeine, were ingested by subjects in a double-blind, crossover study. Stroke volume was significantly increased in the Red Bull group, along with an increase in the diastolic intake velocity (related to ventricular function of the heart). The same observation was made in the caffeine group, but without any increase in the diastolic intake velocity, indicating that the combination of taurine and caffeine produced a different result from that of the individual ingredients. ${ }^{5}$

So far, no data are available for the effect of energy drinks on IOP. However, many of the ingredients have been studied individually. Caffeine (a methylxanthine derivative) has been shown to influence IOP levels in subjects without ${ }^{6}$ and with glaucoma. ${ }^{7}$ With few exceptions, ${ }^{8-10}$ most studies ${ }^{6,7,11-13}$ show that caffeine ingestion from drinks such as coffee causes a transient increase in IOP of approximately $\geq 2 \mathrm{mmHg}$ over a 2-hour period, whereas ingestion of similar drinks without caffeine causes negligible changes in IOP. ${ }^{6,7,12}$ In addition to its effect on IOP, caffeine has been reported to increase blood pressure in some ${ }^{6,14}$ but not all reports. ${ }^{9,15}$ The changes in blood pressure occur within 30 minutes, peak in 1-2 hours, and may persist for more than 4 hours. ${ }^{16}$

On the other hand, taurine (a 2-aminoethane sulfuric acid) has been reported to have hypotensive activity. In a double-blind study, 19 patients with borderline hypertension received a taurine $6 \mathrm{mg}$ supplement or placebo daily for 7 days. Systolic blood pressure in the 10 taurine-treated patients decreased by an average of $9 \mathrm{mmHg}$ compared with a $2 \mathrm{mmHg}$ decrease in the nine patients treated with placebo, and diastolic blood pressure in the taurine-treated patients decreased by an average of $4 \mathrm{mmHg}$ compared with $1 \mathrm{mmHg}$ in the placebo-treated patients. The study showed that taurine relaxes blood vessels by enhancing production of endorphin, resulting in lowered blood pressure. ${ }^{17}$

Taurine has also been shown to influence IOP levels. The mixture of taurine and timolol $0.5 \%$ achieved a significant decrease in IOP $(3.2 \mathrm{mmHg})$ in rabbits 24 hours after instillation. ${ }^{18}$ In addition, Chen et $\mathrm{al}^{19}$ investigating the ability of taurine or taurine-like substances to prevent and treat retinal ganglion cell damage in glaucoma, demonstrated that taurine has the potential to protect retinal ganglion cells against hypoxic damage in vivo by preventing mitochondrial dysfunction.

Primary open-angle glaucoma is a major cause of blindness worldwide..$^{20}$ It is characterized by progressive optic nerve deterioration ultimately leading to blindness if untreated. Little is known of its etiology, but an important established risk factor for the development and progression of primary open-angle glaucoma ${ }^{21,22}$ is elevated IOP. Elevated blood pressure is the single most important predictor of hypertension. Hypertension is an important public health problem worldwide, and one of the leading causes of disability or death, due to stroke, heart attack, and kidney failure. ${ }^{23}$

Because the Sub-Saharan Africans are more predisposed to glaucoma ${ }^{24-27}$ and hypertension, ${ }^{28,29}$ and because these conditions may be modulated by lifestyle factors, efforts to identify activities that may influence IOP and blood pressure levels may be promising in developing primary prevention strategies for these conditions. ${ }^{10}$ We therefore carried out this study to determine the acute effect of drinking a can of Red Bull, which includes taurine and caffeine, on IOP and blood pressure.

\section{Methods \\ Participants}

The participants for the study were students from the University of Cape Coast in Ghana. They were selected at random as the first 50 patients who answered a letter asking if they would volunteer to participate in a study. Thirty students of either gender, aged 18-30 years, were entered into the study. The subjects were randomly divided into two groups. There were 15 subjects (seven females and eight males) in the experimental group and 15 subjects (seven females and eight males) in the control group. The mean age in the experimental and control group was $23.47 \pm 3.16$ years and $23.00 \pm 2.54$ years, respectively. After fully explaining the purpose of the study, written informed consent was obtained from the subjects. In order to be eligible to participate 
in the study, subjects also had to meet a set of inclusion criteria obtained by a complete ophthalmic examination and a questionnaire, ie, absence of any ocular disease, IOP $<22 \mathrm{mmHg}$, blood pressure $<120 / 80 \mathrm{mmHg}$, absence of systemic diseases (including hypertension, diabetes, or vascular disease), evidence of abstinence from caffeine or caffeine beverages, and abstinence from use of any systemic drugs and/or alcohol. Any subject who stated that they had a family or personal history of glaucoma was excluded.

\section{Instruments}

IOP was measured by Goldmann applanation tonometry, and brachial artery systemic blood pressure was assessed by automated sphygmomanometry (Tycos Wall sphygmomanometer, Welch Allyn, Skaneateles Falls, NY).

\section{Procedure}

The study protocol was approved by the Department of Optometry, University of Cape Coast, Ghana. The study was conducted according to the tenets of the Declaration of Helsinki regarding scientific research on human subjects. Subjects abstained from caffeine for 48 hours prior to and during the study. Baseline IOP, and systolic and diastolic blood pressures were measured. The experimental group consumed one can of Red Bull (equivalent to $85 \mathrm{mg}$ caffeine in $250 \mathrm{~mL}$ beverage). IOP and blood pressure measurements were repeated 30, 60, and 90 minutes after ingestion. As a control, 15 of the subjects were required to consume $250 \mathrm{~mL}$ of water, and IOP was measured over the same period.

All participants had a best corrected visual acuity of 6/9 or better in both eyes and had no ocular pathology. Using a Goldmann applanation tonometer, IOP was measured for the right eye only between noon and $2 \mathrm{pm}$ to minimize the influence of diurnal variations in IOP. ${ }^{30} \mathrm{~A}$ group of three consecutive readings with variation of less than $3 \mathrm{mmHg}$ was considered to be an acceptable result and averaged for analysis. One member of the investigative team administered the treatment. This information was not revealed to the examiner measuring the IOP until the end of the investigation. IOP was measured at specific time intervals. The interval between each time period was used to weigh subjects. The scale was calibrated to zero before use.
Sequential examination of arterial blood pressure was also performed at the same time intervals. Three consecutive blood pressure readings, separated by at least 5-minute intervals, were obtained from both arms, with participants in a seated position. The higher mean value in either arm was used in the analysis.

\section{Statistical analysis}

The results for all subjects at each time point, for each group, were combined and presented as the means $( \pm$ standard deviation), to allow for statistical comparison. The absence of any difference between all the measured variables was tested for using the independent $t$-test. The pre-test and post-test data were analyzed using a paired-sample $t$-test. An alpha level of 0.05 was used to determine statistical significance using the SPSS program for Windows, (v 16; SPSS Inc, Chicago, IL).

\section{Results}

We found a high correlation between the measured outcomes for the right and left eye (Pearson's correlation coefficient; $r=0.87$ [data not presented]), indicating a symmetry in data collected from both eyes independently. Therefore, the analyses which follow are limited to the right eye. The mean values and standard deviations of all the measured variables in the pre-tests and post-tests are shown in Tables 1, 2, and 3. There was no significant difference (independent sample $t$-test, $P<0.05$ ) between the experimental and control group with respect to baseline parameters of age, weight, IOP, systolic blood pressure, and diastolic blood pressure, although the mean IOP of the control group was proportionally higher than in the experimental group.

\section{Intraocular pressure changes}

An IOP increase of $\leq 2 \mathrm{mmHg}$ was only observed in two subjects. Eleven subjects had a decrease in IOP of $\geq 2 \mathrm{mmHg}$, while there was no change in IOP in four subjects.

\section{Control group}

An IOP increase of $1 \mathrm{mmHg}$ was observed in three subjects at 30 minutes after ingestion of $250 \mathrm{~mL}$ of water and this was sustained for 60 minutes. With the exception of four

Table I Descriptive statistics (mean \pm standard deviation) for the measured variables of the two groups

\begin{tabular}{lllllll}
\hline Group & Age (years) & Weight (kg) & Baseline & 30 minutes & $\mathbf{6 0}$ minutes & $\mathbf{9 0}$ minutes \\
\hline Experimental & $23.47 \pm 3.16$ & $60.67 \pm 8.0$ & $14.60 \pm 2.50$ & $14.00 \pm 2.24$ & $13.07 \pm 2.58$ & $12.87 \pm 2.59$ \\
Control & $23.00 \pm 2.54$ & $63.47 \pm 12.67$ & $15.87 \pm 3.40$ & $15.67 \pm 3.75$ & $15.40 \pm 3.48$ & $15.67 \pm 3.52$ \\
$P$-value & 0.612 & 0.475 & 0.255 & 0.151 & 0.46 & 0.19 \\
\hline
\end{tabular}


Table 2 Mean ( \pm standard deviation) of systolic blood pressure $(\mathrm{mmHg})$ for each group, at each time point

\begin{tabular}{lllll}
\hline Group & Baseline & $\mathbf{3 0}$ minutes & $\mathbf{6 0}$ minutes & $\mathbf{9 0}$ minutes \\
\hline Experimental & $107.33 \pm 9.61$ & $106.67 \pm 11.75$ & $107.33 \pm 12.33$ & $107.33 \pm 13.87$ \\
Control & $110.00 \pm 8.45$ & $108.67 \pm 8.34$ & $106.67 \pm 9.00$ & $108.67 \pm 9.90$ \\
$P$-value & 0.426 & 0.595 & 0.866 & 0.764 \\
\hline
\end{tabular}

subjects who had a decrease in IOP of $1 \mathrm{mmHg}$ and one subject who had an IOP decrease of $4 \mathrm{mmHg}$, there was no change in IOP observed in the seven subjects of the control group post ingestion.

\section{Experimental group}

Figure 1 and Tables 4 and 5 present the results for analyses of the pre-test and post-test data by the paired samples $t$-test. Ingestion of Red Bull Energy produced an immediate and sustained reduction in IOP in both eyes. Compared with baseline, mean IOP for the experimental group decreased significantly at 60 and 90 minutes (by $1.53 \pm 1.96 \mathrm{mmHg}$ and $1.73 \pm 1.90 \mathrm{mmHg}$, respectively, $P<0.05$ ). Repeated measurement of IOP in the 15 control subjects did not produce any significant change in IOP from baseline at any of the time points measured (two-tailed, paired $t$-test, $P>0.05$ ).

\section{Blood pressure}

The results of the paired samples $t$-test to determine the effect of Red Bull on systolic blood pressure and diastolic pressure are presented in Tables 6-9.

\section{Subgroup analysis}

After consumption of the energy drink, a diastolic blood pressure increase of $\geq 2 \mathrm{mmHg}$ was observed in six subjects, four subjects had a decrease in diastolic blood pressure of $<2 \mathrm{mmHg}$, while no change was observed in five subjects. A systolic blood pressure increase of $\leq 2 \mathrm{mmHg}$ was observed in five subjects after consumption of the energy drink, while three subjects had a decrease in systolic blood pressure, but this was less than $2 \mathrm{mmHg}$. There was no apparent change in systolic blood pressure in seven subjects.

\section{Group analysis}

After consumption of the energy drink, there was a nonsignificant $(P=0.72)$ mean increase in diastolic blood pressure from baseline at 30 minutes, and at 90 minutes from baseline there was a borderline significant increase $(P=0.054)$ in diastolic blood pressure. There was no statistically significant difference from baseline in systolic blood pressure at 30 minutes $(P=0.719), 60$ minutes $(P=1.00)$, and 90 minutes $(P=1.00)$. For the controls, a significant decrease in mean systolic blood pressure from baseline was observed at 60 minutes but not at 30 minutes. No significant change in diastolic blood pressure was detected at any of the time points. Figures 2 and 3 present the graphs for mean changes in systolic blood pressure and diastolic blood pressure, respectively, for the experimental and control groups.

\section{Discussion}

Energy drinks are beverages frequently purported to improve cognitive function and concentration. However, because they contain high amounts of caffeine, which have been shown to influence IOP and blood pressure levels, we examined its effect on these parameters in normal subjects.

Available evidence suggests that caffeinated beverages have different effects on IOP in different groups of individuals. For patients with glaucoma or ocular hypertension, IOP increased significantly, ${ }^{11,12}$ while in normal subjects, IOP either increased, sometimes transiently, ${ }^{6,71-13}$ or no change in IOP was found. ${ }^{8-10,31,32}$ Chandrasekaran et al ${ }^{9}$ found no relationship between IOP and coffee intake in normal subjects. Adams and Brubaker ${ }^{31}$ investigated the effect of orally administered coffee (containing caffeine $400 \mathrm{mg}$ ) on aqueous humor flow in healthy human subjects, and found that caffeine consumption had no effect on aqueous humor formation. In addition, they reported that they did not observe any statistically significant difference in IOP measured before and after coffee intake. In another study, Ozkan et $\mathrm{al}^{32}$ found no significant increase in mean IOP in healthy volunteers after oral administration of caffeine $300 \mathrm{mg}$. In contrast, a study by Ajayi and Ukwade, ${ }^{6}$ which included only Nigerian

Table 3 Mean ( \pm standard deviation) of diastolic blood pressure $(\mathrm{mmHg})$ for each group, at each time point

\begin{tabular}{lllll}
\hline Group & Baseline & $\mathbf{3 0}$ minutes & $\mathbf{6 0}$ minutes & $\mathbf{9 0}$ minutes \\
\hline Experimental & $70.00 \pm 9.26$ & $70.67 \pm 7.99$ & $70.67 \pm 7.07$ & $74.00 \pm 11.21$ \\
Control & $71.33 \pm 10.60$ & $72.00 \pm 7.75$ & $71.33 \pm 6.40$ & $72.00 \pm 7.75$ \\
$P$-value & 0.716 & 0.646 & 0.788 & 0.574 \\
\hline
\end{tabular}




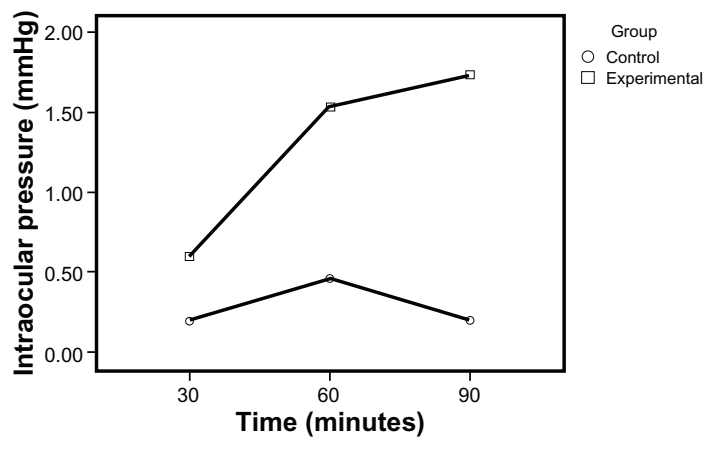

Figure I Intraocular pressure in experimental and control groups.

subjects, reported a significant transient mean IOP increase of $4 \mathrm{mmHg}$ after coffee intake in normal subjects.

Our findings did not support any of the earlier findings because IOP decreased significantly in the experimental group compared with the control group at 60 and 90 minutes after ingestion of Red Bull. Nevertheless, our finding is similar to that of Kang et al, ${ }^{10}$ who reported an inverse association between consumption of an average-sized cup of tea and the risk of primary open-angle glaucoma in a prospective cohort study of 79,120 women and 42,050 normal subjects.

The two main active ingredients in Red Bull energy drink are caffeine and taurine. The hypotensive effects of taurine on blood pressure ${ }^{17}$ and $\mathrm{IOP}^{18}$ have already been demonstrated. However, it would appear that most studies have focused mainly on the ergogenic effects of energy drinks, thus hardly any study in the existing literature has examined the effects on IOP of these compounds combined in an energy drink. On the other hand, with regard to the controversial reports about the effects of caffeine on IOP, it is unclear whether the combination of caffeine and taurine in energy drinks will have a hypotensive or hypertensive effect on IOP. Theoretically, our results can be considered as a possible way to explain the dominant hypotensive effect on IOP of taurine over caffeine when they are combined together. Unfortunately we did not investigate this phenomenon. Furthermore, because this was the first study to examine the effects of an energy drink on IOP, these results must be interpreted cautiously and confirmed by future studies.
We did not find any significant changes in either systolic blood pressure or diastolic blood pressure after consumption of the energy drink. However, there was a significant reduction in mean systolic blood pressure in control subjects at 60 minutes. This finding is noteworthy, given the controversy concerning the effect of drinking water on blood pressure. The effect of energy drinks on blood pressure is also controversial. It was reported in one study that consumption of an energy drink increases blood pressure, ${ }^{4}$ but no change in blood pressure was found in another study, ${ }^{5}$ which is the same as for our study. We found that, although systolic blood pressure fluctuated slightly and the diastolic pressure rose monotonically by $4 \mathrm{mmHg}$ at 90 minutes, these findings were not statistically significant. Given that we have found no increase in IOP and corresponding blood pressure after the ingestion of a caffeinated energy drink, our results indirectly corroborate those of Ajayi and Ukwade, ${ }^{6}$ suggesting that an increase in blood pressure due to ingestion of caffeine may contribute to the increase in IOP. In their investigation, they found that the blood pressure increase occurs much earlier than the IOP increase.

The mechanism by which caffeine may influence IOP is also controversial. One investigator proposed that caffeine, as a phosphodiesterase inhibitor, may increase intracellular cyclic AMP, ${ }^{33}$ stimulating the production of aqueous humor by the ciliary body. Conversely, another investigator hypothesized that caffeine may reduce outflow by decreasing the tone of smooth muscles via adenosine receptor blockade, leading to closure of trabecular pores in the aqueous outflow path. ${ }^{6}$ However, Kurata et al, ${ }^{34}$ using beagle dogs, showed that caffeine increases IOP, possibly by increasing aqueous humor formation, and not by inhibiting aqueous drainage through the trabecular meshwork. Nonetheless, Adams and Brubaker $^{31}$ reported no significant difference in aqueous flow measured hourly for up to 4 hours after administration of caffeine. Our results do not argue directly for or against any of these proposed mechanisms. We can only assume that there was an interaction between the activities of caffeine and taurine in the energy drink to cause a significant reduction in IOP. These findings could stimulate further research on this subject.

Table 4 Paired sample $t$-test for measured right eye intraocular pressure $(\mathrm{mmHg})$ of experimental group

\begin{tabular}{|c|c|c|c|c|c|}
\hline Paired intervals & Mean change in IOP & Standard deviation & Standard error of mean & t-test & $\begin{array}{l}\text { P-value } \\
\text { (two-tailed) }\end{array}$ \\
\hline Pair I IOP $-\mathrm{IOP}_{30}$ & 0.60 & 1.24 & 0.32 & 1.87 & 0.82 \\
\hline Pair $2 \mathrm{IOP}_{0}-\mathrm{IOP}_{60}$ & 1.53 & 1.96 & 0.51 & 3.031 & $0.009 *$ \\
\hline Pair $3 \mathrm{IOP}_{0}-\mathrm{IOP}_{90}$ & 1.73 & 1.90 & 0.50 & 3.52 & $0.003^{*}$ \\
\hline
\end{tabular}

Note: *Statistically significant at an alpha level of 0.05 .

Abbreviation: IOP, intraocular pressure. 
Table 5 Paired sample $t$-test for measured right eye intraocular pressure $(\mathrm{mmHg})$ of control group

\begin{tabular}{|c|c|c|c|c|c|}
\hline Paired intervals & Mean change in IOP & Standard deviation & Standard error of mean & $t$-test & $\begin{array}{l}\text { P-value } \\
\text { (two-tailed) }\end{array}$ \\
\hline Pair I IOP $-1 \mathrm{IOP}_{30}$ & 0.20 & 1.42 & 0.37 & 0.54 & 0.60 \\
\hline Pair $2 \mathrm{IOP}_{0}-\mathrm{IOP}_{60}$ & 0.47 & 1.46 & 0.38 & 1.24 & 0.235 \\
\hline Pair $3 \mathrm{IOP}_{0}-\mathrm{IOP}_{90}$ & 0.20 & 1.78 & 0.46 & 0.44 & 0.670 \\
\hline
\end{tabular}

Abbreviation: IOP, intraocular pressure.

Table 6 Paired sample $t$-test for left eye IOP of experimental group

\begin{tabular}{llllll}
\hline Paired intervals & Mean change in IOP & Standard deviation & Standard error of mean & $\begin{array}{l}\text { t-test } \\
\text { P-value } \\
\text { (two-tailed) }\end{array}$ \\
\hline Pair I IOP-IOP & 0.60 & 1.40 & 0.36 & 0.120 \\
Pair 2 IOP-IOP & 1.00 & 1.70 & 0.44 & 1.66 \\
Pair 3 IOP-IOP & 1.40 & 1.84 & 0.48 & 2.30 & $0.038^{*}$ \\
\hline
\end{tabular}

Note: *Significant at a level of 0.05 .

Table 7 Paired $t$-test to determine the effect of Red Bull ${ }^{\circledR}$ energy drinks on systolic pressure $(\mathrm{mmHg})$ of control group

\begin{tabular}{|c|c|c|c|c|c|}
\hline Paired intervals & Mean change in SBP & Standard deviation & Standard error of mean & $t$-test & $\begin{array}{l}P \text {-value } \\
\text { (two-tailed) }\end{array}$ \\
\hline Pair I $\mathrm{SBP}_{0}-\mathrm{SBP}_{30}$ & 1.33 & 5.15 & 1.33 & 1.00 & 0.33 \\
\hline Pair $2 \mathrm{SBP}_{0}-\mathrm{SBP}_{60}$ & 3.33 & 4.88 & 1.26 & 2.65 & $0.02 *$ \\
\hline Pair $3 \mathrm{SBP}_{0}-\mathrm{SBP}_{90}$ & 1.33 & 7.43 & 1.92 & 0.70 & 0.50 \\
\hline
\end{tabular}

Note: *Statistically significant at an alpha level of 0.05 .

Abbreviation: SBP, systolic blood pressure.

Table 8 Paired $t$-test to determine the effect of Red Bull ${ }^{\circledR}$ energy drinks on diastolic blood pressure $(\mathrm{mmHg})$ of the experimental group

\begin{tabular}{|c|c|c|c|c|c|}
\hline Paired intervals & Mean change in DBP & Standard deviation & Standard error of mean & $t$-test & $\begin{array}{l}P \text {-value } \\
\text { (two-tailed) }\end{array}$ \\
\hline Pair I $\mathrm{DBP}_{0}-\mathrm{DBP}_{30}$ & -0.67 & 7.04 & 1.82 & -0.37 & 0.72 \\
\hline Pair $2 \mathrm{DBP}_{0}-\mathrm{DBP}_{60}$ & -0.67 & 4.58 & 1.18 & 0.56 & 0.58 \\
\hline Pair $3 \mathrm{DBP}_{0}-\mathrm{DBP}_{90}$ & -4.00 & 7.37 & 1.90 & -2.10 & 0.054 \\
\hline
\end{tabular}

Abbreviation: DBP, diastolic blood pressure.

Table 9 Paired $t$-test to determine the effect of Red Bull ${ }^{\circledR}$ energy drink on diastolic blood pressure $(\mathrm{mmHg})$ of control group

\begin{tabular}{llllll}
\hline Paired intervals & Mean change in DBP & Standard deviation & Standard error of mean & $\begin{array}{c}\text { t-test } \\
\text { P-value } \\
\text { (two-tailed) }\end{array}$ \\
\hline Pair I DBP $-\mathrm{DBP}_{30}$ & -0.67 & 7.04 & 1.82 & -0.37 & 0.72 \\
Pair 2 $\mathrm{DBP}_{0}-\mathrm{DBP}_{60}$ & -0.00 & 9.26 & 2.39 & -0.00 & 1.00 \\
Pair 3 $\mathrm{DBP}_{0}-\mathrm{DBP}_{90}$ & -0.67 & 9.61 & 2.48 & -0.27 & 0.79 \\
\hline
\end{tabular}

Abbreviation: DBP, diastolic blood pressure. 


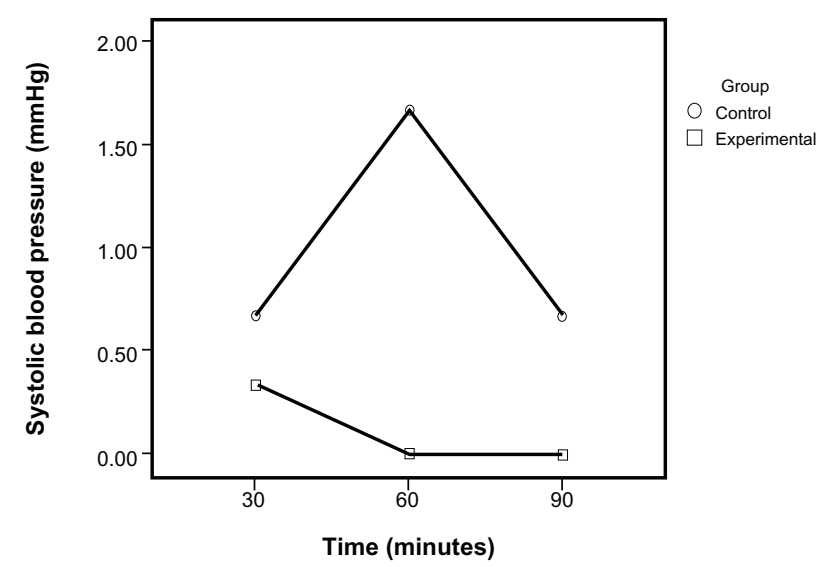

Figure 2 Systolic blood pressure in experimental and control groups.

Although controversial, the expected mild IOP effect of drinking water was not apparent in our study, and would suggest two possible causes. Either our tonometric procedure incorrectly assessed the IOP, or the small fluid challenge volume of $250 \mathrm{~mL}$ used as a control, coupled with inherent biological factors which we were unable to account for, influenced our results. In considering the first possibility, we examined the IOP outcomes for each subject. A group of three consecutive readings with a variation of less than $3 \mathrm{mmHg}$ was considered acceptable and averaged for analysis. We found that, in almost all cases, there was a reproducible trend of IOP results in each eye and a similar trend in both eyes (Pearson's correlation coefficient, $r=0.87$ ), thus justifying the validity and reliability of our tonometric procedure. Goldmann applanation tonometry has an intra observer reliability of $1.7 \mathrm{mmHg}$ and an inter observer variability of $0.4 \mathrm{mmHg} .{ }^{35}$ However, its accuracy can be affected by other inherent biological factors, such as corneal biomechanics and axial length, ${ }^{36,37}$ which we were not able

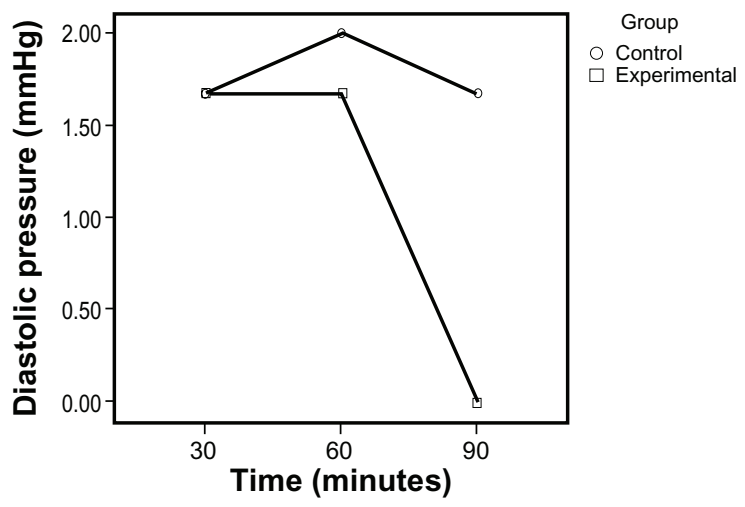

Figure 3 Diastolic blood pressure in experimental and control groups. to account for. Nonetheless, the finding in our study that drinking water was not associated with increased IOP is similar to that found previously by Hsin et al. ${ }^{38}$

In summary, we found that consumption of an energy drink may decrease IOP without changing systemic blood pressure in normal subjects. We hypothesize that this result is a reflection of the effect of the caffeine and taurine combination in energy drinks. Further studies are warranted to explore the biological basis of this hypothesis.

\section{Acknowledgments}

Gratitude is extended to the subjects who participated in this study, as well as to the staff of the Christian Eye Hospital who were instrumental in the collection of data.

\section{Disclosure}

The authors report no conflicts of interest in this work.

\section{References}

1. Malinauskas BM, Aeby VG, Overton RF, Carpenter-Aeby T, BarberHeidal K. A survey of energy drink consumption patterns among college students. Nutr J. 2007;6:35.

2. Bunker M, McWilliams M. Caffeine content of common beverages. J Am Diet Assoc. 1979;74:28-32.

3. Reissig CJ, Strain EC, Griffiths RR. Caffeinated energy drinks - a growing problem. Drug Alcohol Depend. 2009;99:1-10.

4. Steinke L, Lanfear D. Effect of "energy drink" consumption on hemodynamic and electrocardiographic parameters in healthy young adults. Ann Pharmacother. 2009;43:596-602.

5. Baum M, Weiss $M$. The influence of a taurine containing drink on cardiac parameters before and after exercise measured by echocardiography. Amino Acids. 2001;1:75-82.

6. Ajayi OB, Ukwade MT. Caffeine and intraocular pressure in a Nigerian population. J Glaucoma. 2001;10:25-31.

7. Avisar R, Avisar E, Weinberger D. Effect of coffee consumption on intraocular pressure. Ann Pharmacother. 2002;36:992-995.

8. Ricklefs G, Pohls EU. Effect of caffeine containing tablets and Coca-Cola on the intraocular pressure of patients without glaucoma and patients with regulated glaucoma. Klin Monatsbl Augenheilkd. 1969;154:546-551. German.

9. Chandrasekaran S, Rochtchina E, Mitchell P. Effects of caffeine on intraocular pressure: The Blue Mountains Eye Study. J Glaucoma. 2005; 14:504-507.

10. Kang JH, Willett WC, Rosner BA, Hankinson SE, Pasquale LR. Caffeine consumption and the risk of primary open-angle glaucoma: A prospective cohort study. Invest Ophthalmol Vis Sci. 2008;49:1924-1931.

11. Peczon JD, Grant WM. Sedatives, stimulants, and intraocular pressure in glaucoma. Arch Ophthalmol. 1964;72:178-188.

12. Higginbotham EJ, Kilimanjaro HA, Wilensky JT, Batenhorst RL, Hermann D. The effect of caffeine on intraocular pressure in glaucoma patients. Ophthalmology. 1989;96:624-626.

13. Okimi PH, Sportsman S, Pickard MR, Fritsche MB. Effects of caffeinated coffee on intraocular pressure. Appl Nurs Res. 1991;4:72-76.

14. Lotfi K, Grunwald JE. The effect of caffeine on the human macular circulation. Invest Ophthalmol Vis Sci. 1991;32:3028-3303.

15. Okuno T, Sugiyama T, Tominaga M, Kojima S, Ikeda T. Effects of caffeine on microcirculation of the human ocular fundus. Jpn J Ophthalmol. 2002;46:170-176. 
16. Mort JR, Kruse HR. Timing of blood pressure measurement related to caffeine consumption. Ann Pharmacother. 2008;42:105-110.

17. Fujita T, Sato Y. Hypotensive effect of taurine. Possible involvement of the sympathetic nervous system and endogenous opiates. J Clin Invest. 1998;82:993-997.

18. Veselovsky J, Olah Z, Vesela A. Intraocular pressure in rabbits after application of amino acids taurine and arginine with betablocker (timolol). Cesk Slov Oftalmol. 2007;63:320-324. Czech.

19. Chen K, Zhang Q, Wang J, et al. Taurine protects transformed rat retinal ganglion cells from hypoxia-induced apoptosis by preventing mitochondrial dysfunction. Brain Res. 2009;1279:131-138.

20. Quigley H. Number of people with glaucoma worldwide. $\mathrm{Br} J$ Ophthalmol. 1996;80:389-393.

21. Nemesure B, Honkanen R, Hennis A, Wu SY, Leske MC. Incident openangle glaucoma and intraocular pressure. Ophthalmology. 2007;114: 1810-1815.

22. Leske MC, Connell AMS, Wu S-Y, et al. Incidence of open-angle glaucoma: The Barbados Eye Studies. Arch Ophthalmol. 2001;119: 89-95.

23. Kearney PM, Whelton M, Reynolds K, Muntner P, Whelton PK, He J. Global burden of hypertension: Analysis of worldwide data. Lancet. 2005;365:217-223.

24. Olurin O. Causes of blindness in Nigeria - a study of 1000 hospital patients. West Afr Med J. 1973;22:97-107.

25. Potter AR. Causes of blindness and visual handicap in the Central African Republic. Br J Ophthalmol. 1991;75:326-328.

26. Kayembe L. Causes of blindness in Zaire. J Fr Ophtalmol. 1984;7: 393-398. French.

27. Balo K, Negrel DA. Causes of blindness in Togo. J Fr Ophtalmol. 1989;12:291-295. French.

28. Amoah AG. Hypertension in Ghana: A cross-sectional community prevalence study in Greater Accra. Ethn Dis. 2003;16:894-899.
29. Addo J, Smeeth L, Leon D. Hypertension in Sub-Saharan Africa. A systematic review. Hypertension. 2007;50:1012-1018.

30. Hasegewa K, Ishida K, Sawada A, Kawase K, Yamamoto T. Diurnal variation of intraocular pressure in suspected normal-tension glaucoma. Jpn J Ophthalmol. 2006;50:449-454.

31. Adams BA, Brubaker RF. Caffeine has no clinically significant effect on aqueous humor flow in the normal human eye. Ophthalmology. 1990;97:1030-1031.

32. Ozkan B, Yuksel N, Anik Y, Altintas O, Demirci A, Caglar Y. The effect of caffeine on retrobulbar hemodynamics. Curr Eye Res. 2008;33: 804-809.

33. Benowitz NL. Clinical pharmacology of caffeine. Annu Rev Med. 1990; 41:27-28

34. Kurata K, Fujimoto H, Tsukuda R, Suzuki T, Ando T, Tokuriki M. Aqueous humor dynamics in beagle dogs with caffeine-induced ocular hypertension. J Vet Med Sci. 1998;60:737-739.

35. Kotecha A, White ET, Shewry JM, Garway-Heath DF. The relative effects of corneal thickness and age on Goldmann applanation tonometry and dynamic contour tonometry. Br J Ophthalmol. 2005;89: $1572-1575$.

36. Stodtmeister R. Central corneal thickness on GAT (Goldman applanation tonometry accuracy). J Glaucoma. 2002;11:543.

37. Lleo A, Marcos A, Calatayud M, Alonso L, Rahhal SM, SanchisGimeno JA. The relationship between central corneal thickness and Goldmann applanation tonometry. Clin Exp Optom. 2003:86: 104-108.

38. Hsin Y, Wen-Ming H, Chou P, et al. Intraocular pressure measured with a noncontact tonometer in an elderly Chinese population: The Shihpai Eye Study. Arch Ophthalmol. 2005;123:381-386.
Clinical Optometry

\section{Publish your work in this journal}

Clinical Optometry is an international, peer-reviewed, open access journal publishing original research, basic science, clinical and epidemiological studies, reviews and evaluations on clinical optometry. All aspects of patient care are addressed within the journal as well as the practice of optometry including economic and business analyses. Basic and clinical

Submit your manuscript here: http://www.dovepress.com/clinical-optometry-journal

\section{Dovepress}

research papers are published that cover all aspects of optics, refraction and its application to the theory and practice of optometry. The manuscript management system is completely online and includes a very quick and fair peer-review system, which is all easy to use. Visit http://www.dovepress. com/testimonials.php to read real quotes from published authors. 